\title{
50 years of radiation protection and nuclear power in Switzerland: a brief history
}

\author{
Hansruedi Völkle \\ Section for Environmental Radioactivity, \\ Division for Radiation Protection, \\ Swiss Federal Office of Public Health, c/o Physics Department, \\ University of Fribourg, Chemin du Musée 3, \\ $\mathrm{CH}-1700$ Fribourg, Switzerland \\ E-mail: hansruedi.voelkle@bag.admin.ch
}

\begin{abstract}
This article presents a short history of research in nuclear physics as well as of 50 years of nuclear power and radiation protection in Switzerland. After the International Conference 'Atoms for Peace' held in 1955 in Geneva the first research reactor was installed in Switzerland. A national environmental radioactivity monitoring programme was started in 1956. Today some $40 \%$ of the electricity is produced by nuclear power. In 1986, the southern part of Switzerland was most burdened by radioactive fallout from the Chernobyl Accident. Fortunately, the integral average radiation doses to the population remained below 0.5 milli-Sievert. As in other western countries there was a vigorous debate in Switzerland in the 1980s and 1990s about nuclear power, nuclear safety and the safe storage of radioactive waste.
\end{abstract}

Keywords: environmental radioactivity; nuclear physics; nuclear power; radiation protection.

Reference to this paper should be made as follows: Völkle, H. (2006) '50 years of radiation protection and nuclear power in Switzerland: a brief history', Atoms for Peace: An International Journal, Vol. 1, Nos. 2/3, pp.239-244.

Biographical notes: Hansruedi Völkle gained his Diploma in Physics from Fribourg University in 1974. Since 1973, he has been working for the Environmental Radioactivity Section in Fribourg of the Swiss Federal Office of Public Health, from 1987 to the end of 2005, as head of the section. He gained his PhD in 1980 from Fribourg University and 1996 the 'Venia Legendi' (Habilitation); in 2001 he was appointed professor. He is lecturing in radiation protection and nuclear physics. He is a member of the Swiss-German 'Fachverband für Strahlenschutz', the Swiss-German Commission on Nuclear Safety and is Senator of the Swiss Academy of Sciences.

\section{The beginning}

Nuclear physics and nuclear energy have for many years been important topics in research and technology in Switzerland. As early as in the first decade of the 20th century, Albert Gockel from the University of Fribourg was measuring the ionisation 
of the air up to an altitude $4500 \mathrm{~m}$ by using a gas balloon. He was among the discoverers of cosmic radiation. Unfortunately, the Austrian Viktor F. Hess received the Nobel Prize in 1936 in his place. Paul Scherrer, at the Swiss Federal Institute of Technology in Zurich, was a pioneer in nuclear physics and an enthusiastic promoter of nuclear energy. He trained a whole generation of physicists. In 1937 he missed the discovery of nuclear fission: in his research group, he irradiated thorium with neutrons, but did not pay attention to the resulting fission products. Otto Hahn, Fritz Strassmann and Liese Meitner made this discovery in the following year at the Kaiser Willhelm Institute in Berlin. In 1945, Scherrer had published an article in the Neue Zürcher Zeitung describing an 'Atomic Machine', a graphite-moderated, gas-cooled nuclear reactor, using natural uranium, which already had the main characteristics of today's reactor. In 1953, US President Dwight D. Eisenhower opened up nuclear energy for peaceful use. An international conference called 'Atoms for Peace' was organised in 1955, in Geneva. An operating nuclear reactor was exhibited to the public for the first time. Scherrer was clever enough to know that this reactor, which had been transported to Switzerland by air, could not be returned to the USA by the same means because of the radioactivity produced by the reactor in operation for several weeks. He suggested, therefore, that the USA should sell it to Switzerland. A reactor research institute, the 'Reaktor AG', was created at Wuerenlingen, later called Swiss Federal Institute for Reactor Research and presently named the Paul Scherrer Institute. This swimming pool reactor has for many years served for nuclear physics research and for radioisotope production with medical applications.

\section{Environmental monitoring}

Environmental monitoring of radioactivity started in Switzerland in 1956 with the appointment by the Swiss Federal Council of the Federal Commission for Radioactivity Surveillance. The reason was the concern about the constant rise in environmental radioactivity in the Northern Hemisphere as a consequence of the nuclear weapon tests in the 1950s and 1960s. This led to international agreements, first to abandon atmospheric tests (1963: PTBT), then to limit the power of tests to $150 \mathrm{kT}$ (1974: TTBT) and finally to a 'Comprehensive Test Ban Treaty' (1996: CTBT).

As a consequence, Switzerland, similar to other countries, installed a network to monitor the radioactivity of air, rain, water, soil, grass, milk and other food, completed by measurements of the radionuclide content in the human body. Paul Huber, later his brother Otto Huber and then Heinz Hugo Loosli presided over this commission, which in 1957 addressed its first report to the Federal Council. In the following years, the monitoring programme was constantly improved and adapted. The programme first focused on the measurement of the atomic bomb fallout. Later, nuclear reactors, research institutions, industries and hospitals using radionuclides became of more interest. Today, automatic networks are operated for dose rate measurements and aerosol radioactivity, completed by high volume air samplers and in situ Gamma Spectrometry. Since 1986, the Federal Office of Public Health has been responsible for the environmental monitoring programme and for informing the public about radioactivity and radiation protection. 
The first law on the 'Peaceful use of atomic energy and on radiation protection' (Atomgesetz) dates from December 23rd 1959. In March 1991, a new radiation protection law was enforced. The first radiation protection ordinance, dating from April 1963, was renewed in 1976 and 1994. The last version adopted the new ICRP-Recommendations of publication number 60 (1991), concerning, in particular, the dose limit for the public of 1 milli-Sievert ( $\mathrm{mSv}$, the unit for the effective dose) per year and the one for workers exposed to radiation of $20 \mathrm{mSv}$ per year. A new law on nuclear energy went into force in February 2005 together with an ordinance on nuclear energy.

\section{Nuclear power in Switzerland}

In 1946, a Swiss committee for atomic energy was formed with Paul Scherrer as first president. In the 1950s, the USA, the USSR and the UK started running their first nuclear reactor for electric power production. Scherrer's committee also studied the commercial use of nuclear power. The Swiss industry, motivated by Paul Scherrer, planned to develop its own reactor design. This led to the construction of the experimental nuclear power station in Lucens, some $30 \mathrm{~km}$ NE of Lausanne. A heavy water moderated, $\mathrm{CO}_{2}$ cooled, pressure tube reactor with natural uranium and an output of $8.5 \mathrm{MWe}$ was built in an underground cavern. It went into operation in 1968 but, after a serious accident due to corrosion of some of the fuel elements, had to be shut down definitively in January 1969. Fortunately, the incident took place in winter and only short-lived noble gases were released with only a slight impact on the environment. It took about 10 years to complete the dismantling of this experimental power station, after which the cavern was finally filled with concrete in 1995 and the site was dismissed from nuclear regulation.

Switzerland ordered commercial nuclear power reactors from the USA (Westinghouse, General Electric) and from Germany (KWU). Since 1969, four nuclear power stations have been operating at Beznau (1969 and 1971, two PWR's with $365 \mathrm{WMe}$ each), Mühleberg (1972, a BWR with $355 \mathrm{MWe}$ ), Goesgen (1979, a PWR with $970 \mathrm{WMe}$ ) and Leibstadt (1984, a BWR with $1165 \mathrm{MWe})$. Today they produce approximately $40 \%$ of the electric power consumed in Switzerland, the remainder being almost exclusively hydraulic power. Some electricity, however, is imported from French nuclear power stations. The increase in cost of the nuclear power stations is noticeable: while the two Westinghouse plants cost some 350 million Swiss Francs each, the price of the last one was 4.8 billion Swiss Francs. The licensing authority for nuclear power plants is the Swiss Federal Office of Energy and the Nuclear Safety Inspectorate in Würenlingen.

After a mostly euphoric period, the Swiss population became more critical about nuclear energy in the following years, so several projects for further nuclear power stations were abandoned, mainly due to protests from nuclear energy opponents. A condition set up by the Swiss authorities for further exploitation of nuclear power was to be able to demonstrate that, from the technical point of view, radioactive waste could be safely stored in our country and for long enough to let it decrease to the level of natural radioactivity. This was done by the so called project 'Gewähr'. Nevertheless, from the political point of view, it has become more and more difficult 
in the last years to obtain public approval for radioactive waste disposal facilities. In fact, the public rejected a disposal site for radioactive waste near Wellenberg in 2002. Resistance is also increasing among the inhabitants of the Benken region, Canton of Zurich and the neighbouring municipalities in Germany, against possible waste disposal. In 1990, the Swiss population voted in favour of a 'Nuclear Energy Moratorium' for 10 years. In the latter years, however, a change in public opinion towards nuclear power has become apparent: the initiative 'Moratorium Plus' was clearly rejected in 2003 by the Swiss population and a second initiative 'Power without Atom' was even rejected by two-thirds of the voting citizens. Now the Swiss power industry is considering a foreseeable shutdown of the older Swiss nuclear plants, in view of a revival of nuclear energy, probably encouraged by the plans in Finland and France to construct an EPR (European Pressurised Reactor).

\section{Radioisotopes in industries, medicine and research}

In Switzerland, radioactive substances are mainly used in the watch industries, formerly ${ }^{226} \mathrm{Ra}$ for dials, and in the last decades exclusively tritium. However, as more and more non-radioactive phosphors became available, the consumption of tritium for luminous paint has decreased by a factor of 100 in the last 10 years. Some of the watch manufacturers have already completely abandoned tritium for luminous paint.

In medicine, various radionuclides are used for diagnosis as well as for therapy. The largest portion is constituted of ${ }^{131} \mathrm{I}$ for thyroid diagnosis and treatment. Up to activities of $200 \mathrm{MBq}$, it is used ambulatory. $\left(\mathrm{MBq}=10^{6} \mathrm{~Bq} ; \mathrm{Bq}=\right.$ Becquerel is the unit for radioactivity with $1 \mathrm{~Bq}=1$ disintegration per second). Above this value the patients must be isolated for at least $48 \mathrm{~h}$ in special therapy rooms and the waste water only evacuated after having decreased to a level fixed by the Federal Office of Public Health. This office is the licensing authority in radiation protection for Medicine, Industry, Trade and Research.

In the field of research, apart from the already mentioned Paul Scherrer Institute and many other federal Institutions and Universities, the most important research facility is CERN (Organisation Européenne pour la recherche nucléaire) near Geneva, over Swiss and French territory.

\section{The Chernobyl accident}

The severe reactor accident of April 261986 in the Russian nuclear power station of Chernobyl released large amounts of radioactive substances into the atmosphere. Even convinced nuclear energy proponents were shocked. In the most serious accident that has ever arisen in a civilian nuclear installation, the reactor was completely destroyed by an explosion and burned for over 10 days. The released radioactivity was deposited mainly in today's independent States of Ukraine, Byelorussia and the Russian Federation. Part of it moved westwards and, from April 30th, Switzerland was also affected. The cloud reached a measuring station in eastern Switzerland at 2 o'clock in the morning. Rain fell while the radioactive cloud passed 
over the Ticino region. This part of the country was therefore affected the most with activities up to $40,000 \mathrm{~Bq}$ of ${ }^{137} \mathrm{Cs}$ deposited per $\mathrm{m}^{2}$. The region near Lake Constance was somewhat less affected together with some parts of the Jura Mountains. The contamination of central and western Switzerland was significantly lower, even lower than the activity deposited in the fallout period of the 1950s and 1960s.

The radiation doses were mainly due to following radionuclides: ${ }^{131} \mathrm{I}$ with a half-life of 8 days, and the two caesium nuclides ${ }^{134} \mathrm{Cs}$ and ${ }^{137} \mathrm{Cs}$ with half-lives of 2 and 30 years respectively. In the first year after the accident, the average radiation dose to the Swiss population was $0.2 \mathrm{mSv}$. The total dose over all subsequent years mounts to $0.5 \mathrm{mSv}$, whilst the integral contribution attributed to atomic bomb test fallout was approximately $1.2 \mathrm{mSv}$. The consumption of contaminated food contributed to most of the dose, whereby the two caesium nuclides consisted of $40 \%$ together and ${ }^{131}$ I about $30 \%$ of the dose. In the regions mostly concerned - in particular with self-support farmers - the doses were approximately 10 times higher. The only severe protection measure taken was the ban on fishery in the Lake of Lugano between September 1986 and July 1988. Apart from this only a few recommendations were issued: they involved pregnant women, nursing mothers and small infants refraining from the consumption of fresh milk and vegetables, the consumption of cistern water as well as of sheep milk and sheep cheese in certain areas and, renouncing the slaughter of sheep and goats until August 1986. In agreement with the European Community, Switzerland adopted a limit of $370 \mathrm{~Bq}$ per $\mathrm{kg}$ for the two caesium isotopes for milk, cream, milk products and children's food. For the remaining food, a value of $600 \mathrm{~Bq}$ per $\mathrm{kg}$ was set up. For mushrooms imported from Eastern European countries a radioactivity certificate is still required.

Today, only traces of the long-lived ${ }^{137} \mathrm{Cs}$ remains detectable in some regions and some food of minor importance, such as game meat and certain wild mushrooms. To estimate the health impact on the Swiss population, the $0.5 \mathrm{mSv}$ specified above have to be compared to the natural radiation doses we absorb in one generation of $120 \mathrm{mSv}$ approximately. This is an increase of about $0.5 \%$ and will not lead to a significant increase in cancer incidence in our country.

The Chernobyl reactor accident led to an improvement in international cooperation. Excellent examples of this cooperation are the INES classification of nuclear accidents, the Assistance Convention of the IAEA, the harmonisation of protection measures to be taken after an accident and finally a regular exchange of information and monitoring data between the countries.

\section{Retrospective}

From the very beginning, the protection of man and the environment has been the main objective of radiation protection and environmental monitoring in Switzerland. Good results have been obtained by the implication in the monitoring programme of all federal and regional institutions, universities and research facilities, having scientific competence and measuring capacity. Fortunately, so far no dangerous increase in doses to the population have been detected. The average dose to the Swiss population is mainly due to natural sources: $0.45 \mathrm{mSv}$ per year from terrestrial radiation, $0.35 \mathrm{mSv}$ per year each from cosmic radiation and from radionuclides in 
the human body, and $1.6 \mathrm{mSv}$ per year from radon and daughter products in dwellings. Radon is the most important contribution to the population dose and is responsible for up to $10 \%$ of lung cancer in our country. Between 1 and $2 \%$ of the population get more than $10 \mathrm{mSv}$ from it. The most important contribution from artificial sources of radiation is $1 \mathrm{mSv}$ from medical applications in X-ray diagnosis. All other artificial sources contribute together to only $0.2 \mathrm{mSv}$, i.e. releases from nuclear power stations, industries and hospitals, radionuclides in consumer products, etc. Radiation doses to people living near Swiss nuclear power stations are, even under most conservative assumptions, below $0.01 \mathrm{mSv}$ per year. The contribution from the Chernobyl accident and the atomic bomb test fallout amounts today to less than $0.01 \mathrm{mSv}$ per year.

According to the national dose registry of the Swiss Federal Office of Public Health, some 68,000 radiation workers in nuclear power stations, hospitals, medical cabinets, industries and research institutions accumulated in 2004 a collective dose of 6.16 person-Sieverts. The average dose per person is $0.09 \mathrm{mSv}$. The collective dose of the workers in nuclear power stations, due to continuous optimisation in radiation protection, has diminished from 6 to 12 person-Sievert per year and per plant to below 2 person-Sievert, the average dose in 2004 being $1.1 \mathrm{mSv}$ per person.

\section{A view to the future}

In many countries discussions are under way as to whether nuclear power should continue to be used in the near future. However, a certain reconsideration is to be recognised in view of the limited supplies of fossil fuels and the imminent climate changes due to the rising carbon dioxide content of the atmosphere. Even if renewable energy sources could and should be used more efficiently, we probably won't be able to renounce the use of nuclear power for the next two generations at least, until fusion power is technically available. Hydrogen will certainly be a future source of energy, particularly for traffic, and it could be produced by nuclear reactors of a fourth generation. A further problem, which must be solved by our generation, is the safe storage of radioactive waste at least until it has decreased to the level of natural radioactivity. An aspect that particularly concerns the authorities is their reliability among the public and how to communicate about radioactivity, nuclear safety, ionising radiation and radiation risks. Finally, the question occurs to us, in view of the shortage of public finances in many countries, will it be possible in the future to maintain systematic monitoring to the same extent as has been accomplished so far? 